\title{
Chemical epidural abscess: case report
}

\author{
N. VIJAYAN AND P. M. DREYFUS \\ From the Department of Neurology, School of Medicine, University of California, Davis, and the Neurology \\ Service, Sacramento Medical Center, Sacramento, California, U.S.A.
}

SUMMARY Spinal epidural abscess accompanies blood-borne infection, vertebral osteomyelitis, or an overlying cutaneous source of infection. This report documents the development of a noninfective epidural abscess where the inflammatory response was induced by the highly irritant contents (keratin and cholesterol) of an underlying epidermoid. This was associated with aseptic meningitis.

Since the original clinical description by Albers in 1833 and the classical anatomical study by Dandy in 1926 , a number of reports and reviews of spinal epidural abscess have appeared in the literature (Heusner, 1948; Dús, 1960; Gindi and Fairburn, 1969). Similarly, subdural epidermoid cysts complicated by spontaneous or surgically induced chemical meningitis have been described (Critchley and Ferguson, 1928; Olivecrona, 1932; Decker and Gross, 1967; Cantu and Wright, 1968). Congenital dermal sinuses which communicate with intraspinal dermoid or epidermoid cysts associated with recurrent meningitis are well-known clinical entities (List, 1941; Mount, 1949). It is the purpose of this brief communication to report a case in which an aseptic, chemically induced epidural abscess was caused by an underlying epidermoid cyst within the subarachnoid space, in the absence of a communicating sinus tract.

\section{CASE REPORT}

The patient was a 5 year old Mexican-American girl who had previously been admitted to the hospital at ages $2 \frac{1}{2}$ and 3 years because of febrile convulsions. Lumbar punctures were performed on both occasions. These were described as yielding normal cerebrospinal fluid.

She was readmitted to the hospital on 13 February 1969 because of fever, questionable nuchal rigidity, irritability, limping, and pain in both knees. On admission to the hospital, nuchal rigidity was no longer present and neurological examination was reported as normal. Temperature was $39^{\circ} \mathrm{C}\left(103 \cdot 4^{\circ} \mathrm{F}\right)$. White cell count was $15,800 / \mathrm{cu}$. mm with a slight shift to the left. All other laboratory examinations were normal except for a lumbar puncture which revealed normal pressure and slightly turbid fluid containing 1,842 white cells/cu. $\mathrm{mm}$ of which $93 \%$ were polymorphonuclear leucocytes and the rest lymphocytes.
The protein content was $145 \mathrm{mg} / 100 \mathrm{ml}$. and the sugar $20 \mathrm{mg} / 100 \mathrm{ml}$. (concomitant blood sugar $100 \mathrm{mg}$ / $100 \mathrm{ml}$.). A smear of the sediment and cultures were negative. The patient was treated with parenteral ampicillin and the temperature declined after four days. The patient remained irritable and pain in both knees persisted. Lumbar puncture once again revealed slightly turbid fluid under normal pressure, containing 3,500 leucocytes/cu. mm of which $91 \%$ were polymorphonuclear leucocytes and the remainder lymphocytes. Sugar was $32 \mathrm{mg} / 100 \mathrm{ml}$. and the protein content $150 \mathrm{mg} /$ $100 \mathrm{ml}$. Smear and cultures were negative. Blood cultures were also negative. An intermediate strength PPD tuberculin test was negative.

Clinical improvement was apparent during the ensuing days. A subsequent lumbar puncture was traumatic. The fluid contained 14,700 red blood cells/cu. mm and 190 white cells/cu. mm, of which $51 \%$ were polymorphs. The sugar content was $40 \mathrm{mg} / 100 \mathrm{ml}$. and the protein $213 \mathrm{mg} / 100 \mathrm{ml}$. Smears of the sediment and repeat cultures were negative.

The patient remained asymptomatic for a week, after which she began to limp and again to complain of pain in both knees and low back. She was anorexic and irritable. While in bed, the patient tended to keep both hips and knees flexed. There were apparently no headaches, vomiting, or nuchal rigidity. The temperature had once again risen to $37 \cdot 8^{\circ} \mathrm{C}\left(100^{\circ} \mathrm{F}\right)$. In the standing position a loss of the normal lordosis with paravertebral muscle spasm and tenderness over L3, 4, and 5 vertebral spines were noted. Kernig's sign was present bilaterally. Passive movements of both hips and knees showed full range of motion. No weakness or muscle wasting could be detected in either lower extremity. Deep tendon reflexes were normal and symmetrical and the plantar responses were flexor bilaterally. No alteration of sensation could be elicited. Examination of cranial nerves and both upper extremities was normal. The bladder was visibly distended and the patient could void only small amounts of urine. Radiographs of the chest, spine, hips, and knees were normal. Laboratory studies revealed a 
normal white count, a haemoglobin of $9.4 \mathrm{~g} / 100 \mathrm{ml}$. , and normal urine. Lumbar puncture showed slightly turbid fluid under normal pressure containing 267 white cells/ cu. mm, of which $66 \%$ were polymorphonuclear leucocytes and the remainder lymphocytes. The protein was $238 \mathrm{mg} / 100 \mathrm{ml}$. and the sugar content $42 \mathrm{mg} / 100 \mathrm{ml}$. (blood sugar $80 \mathrm{mg} / 100 \mathrm{ml}$.). No organisms were seen on smears and India ink preparations; cultures for microorganisms including $M$. tuberculosis and fungi were negative.

A few days later the patient was found to have decreased knee and ankle jerks and diminished rectal tone. By the next morning she was incontinent of urine and faeces and knee and ankle jerks could no longer be elicited. Plantar and dorsiflexion of both ankles was diminished. In order to confirm the suspected diagnosis of epidural abscess, careful aspiration of the L4-5 interspace was carried out. Two millilitres of pus were removed. This was followed by surgical exploration of the epidural space at L3, 4, and 5 vertebrae. No dermal sinus or other tract was found. A small quantity of pus and some granulation tissue were removed. The underlying dura was found to be thickened but intact. The pus revealed no organisms on either smear or cultures. Histological examination of the epidural granulation tissue showed a large number of multi-nucleated, foreign-body giant cells (Fig. 1).

The patient continued to worsen after surgery. Knee and ankle jerks remained absent and she continued to be incontinent of faeces. Cystometrographic examination revealed a neurogenic bladder. Ten days later the patient was operated on again because of continued neurological deterioration, evidenced by increasing weakness and atrophy of thigh and distal leg muscles. The epidural space was found to be free of pus; the dura was intact but appeared tense. The latter was opened opposite $L 3,4$, and 5 spinous processes and an oval-shaped cyst measuring $0.5 \times 2.0 \mathrm{~cm}$ was revealed. This cyst had been draining into the subarachnoid space, causing a severe degree of adhesive arachnoiditis involving the roots of the cauda

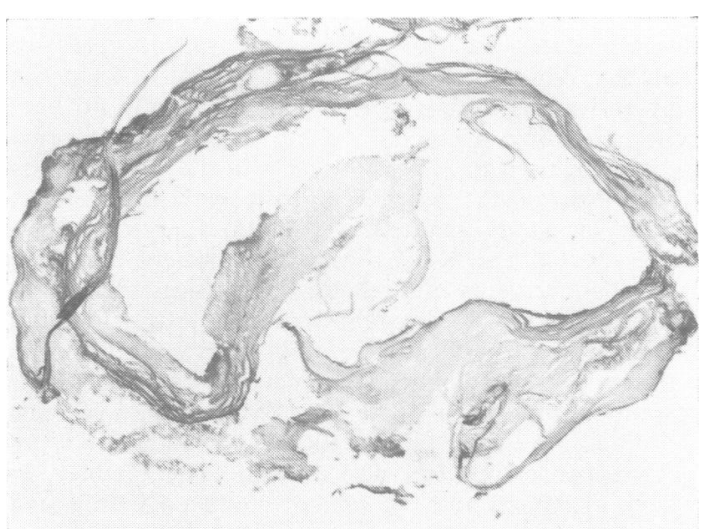

FIG. 1. Cross-section through the cyst. equina. The cyst was removed and some of the adhesions freed. Histological examination of the cyst revealed aD typical epidermoid cyst (Fig. 2).

Postoperatively, the wound healed normally, thes patient's pain disappeared, and there was no further pro gression of neurological signs. However, despite treat -0 ment with steroids and active physical rehabilitation the patient made a poor functional recovery.

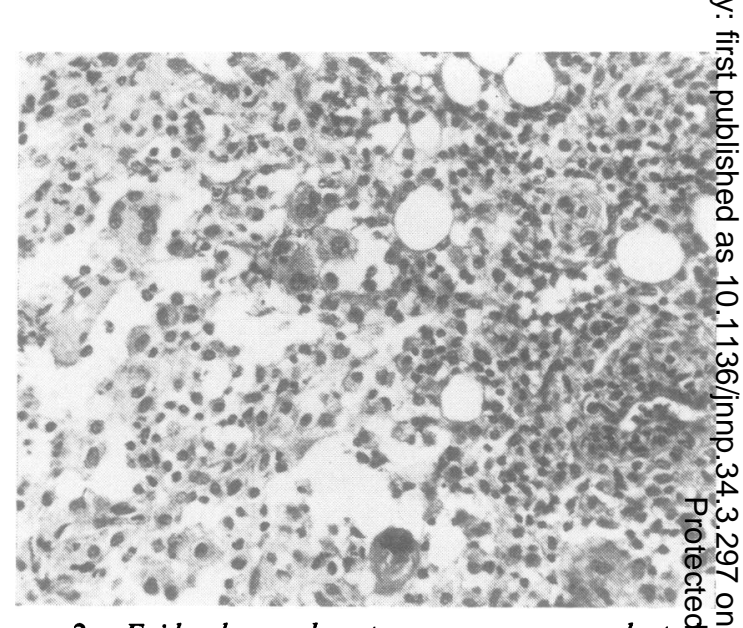

FIG. 2. Epidural granulomatous process removed at hie time of the first operation. Several multi-nucleated giant cells are seen scattered throughout the field.

\section{DISCUSSION}

Spinal epidermoid and dermoid cysts result from ectodermal dysplasia occurring during the develop ment of the neural tube (Walker and Bucy, 1934 Ingraham and Matson, 1961). According to Lis? (1941) the time at which this occurs determineso whether a dermoid or an epidermoid cyst develops subsequently. In the early phase of development, the dysplastic cells are 'multi-potent' and a dermoid cyst containing all of the dermal elements develops At a later phase, the cells are 'uni-potent' and hence. an epidermoid cyst develops. Trauma has beer? invoked as an aetiological factor in the development. of epidermoid cysts in the lumbar region. According to Choremis, Economos, Papadatos, and Gargoulas (1956) and Blockey and Schorstein (1961) repeated lumbar punctures may drive fragments of epidermis into the subarachnoid space; these, subsequently․ㅡ․ proliferate and develop into an epidermoid cyst. In all of their reported cases, the cyst became sympto os matic three to 10 years after the initial lumbaro puncture. In the case under discussion, the first lumbar puncture was performed two and a halfo 
years before the onset of symptoms. It is, therefore, conceivable that the initial lumbar puncture was responsible for the cyst which was ultimately removed.

Whereas dermoid cysts have a predilection for the lumbosacral region, epidermoid cysts are evenly distributed along the extent of the spinal canal (List, 1941). When symptomatic, these cysts behave like any other intraspinal mass, causing pressure on the nerve roots. On the other hand, when the contents of a cyst discharge into the subarachnoid space, a chemical meningitis ensues. In the presence of a dermal sinus, recurrent meningitis or epidural infection may occur.

In our case, an epidural abscess developed in the absence of any visible sinus tract. We postulate that an embryologically determined cyst was inadvertently punctured during one of the initial lumbar punctures and that the cyst contents were thus allowed to flow into the epidural space, setting up an aseptic, granulomatous inflammatory process. The possibility of a small communication between the cyst and the epidural space which was subsequently sealed off by the inflammatory reaction cannot be excluded.

It is of interest to note that the material which was removed from the epidural space at the time of the first operation contained a large number of multinucleated giant cells. This 'foreign body' reaction may have been caused by the spillage of the cyst contents into the epidural space. Cholesterol crystals and keratinaceous material which are contained in these cysts are highly irritative in nature. The unusual combination of an epidermoid cyst accompanied by an epidural abscess in the absence of a communicating dermal sinus was responsible for the fact that the correct diagnosis was initially overlooked and that the chemical meningitis was not treated with steroids, which are reported to be highly effective in this type of meningitis.

\section{REFERENCES}

Albers (1833). Die Entzündung der Harten Haut des Rückenmarks, Perimeningitis Spinalis. J. chir. Augenheilk., 19, 347.

Blockey, N. J., and Schorstein, J. (1961). Intraspinal epidermoid tumours in the lumbar region of children. J. Bone Jt Surg., 43-B, 556-562.

Cantu, R. C., and Wright, R. L. (1968). Aseptic meningitic syndrome with cauda equina epidermoid tumor. J. Pediat., 73, 114-116.

Choremis, C., Economos, D., Papadatos, C., and Gargoulas, A. (1956). Intraspinal epidermoid tumours (cholesteatomas) in patients treated for tuberculous meningitis. Lancet, 2, 437-439.

Critchley, M., and Ferguson, F. R. (1928). The cerebrospinal epidermoids (cholesteatomata). Brain, 51, 334-384.

Dandy, W. E. (1926). Abscesses and inflammatory tumors in the spinal epidural space (so-called pachymeningitis externa). Arch. Surg., 13, 477-494.

Decker, R. E., and Gross, S. W. (1967). Intraspinal dermoid tumor presenting as chemical meningitis. J. Neurosurg., 27, 60-62.

Dus, V. (1960). Spinal peripachymeningitis (epidural abscess), J. Neurosurg., 17, 972-983.

Gindi, E. S., and Fairburn, B. (1969). Intramedullary spinal abscess as a complication of a congenital dermal sinus. J. Neurosurg., 30, 494-497.

Heusner, A. P. (1948). Nontuberculous spinal epidural infections. New Engl.J. Med., 239, 845-854.

Ingraham, F. D., and Matson, D. D. (1961). Neurosurgery of Infancy and Childhood. Thomas: Illinois.

List, C. F. (1941). Intraspinal epidermoids, dermoids, and dermal sinuses. Surg. Gynec. Obst., 73, 525-538.

Mount, L. A. (1949). Congenital dermal sinuses. J. Amer. med. Ass., 139, 1263-1268.

Olivecrona, H. (1932). On suprasellar cholesteatomas. Brain, $55,122-134$.

Walker, A. E., and Bucy, P. C. (1934). Congenital dermal sinuses: A source of spinal meningeal infection and subdural abscesses. Brain, 57, 401-421. 